Rev. Adm. Saúde Vol. 17, № 69, Out. - Dez. 2017

http://dx.doi.org/10.23973/ras.69.67

ARTIGO DE REVISÃO

\title{
Fatores relacionados ao absenteísmo na equipe de enfermagem: uma revisão integrativa
}

Factors related to absenteeism in nursing staff: an integrative review

\author{
Viviane Santos Mendes Carneiro1, Raphael Neiva Praça Adjuto²
}

1. Enfermeira, especialista em urgência e emergência, especialista em gestão em enfermagem. Enfermeira do Hospital das Clínicas da Universidade Federal de Goiás

2. Enfermeiro, especialista em terapia intensiva, especialista em saúde coletiva. Enfermeiro residente em terapia intensiva da Escola Superior de Ciências da Saúde, Brasília - DF

\section{RESUMO}

Introdução. O absenteísmo refere-se à frequência ou duração do tempo de trabalho perdido quando os profissionais não comparecem ao trabalho e corresponde às ausências quando se esperava que os mesmos estivessem presentes. Na área da saúde, este assunto tem despertado cada vez mais o interesse dos administradores hospitalares, por ser um dos fatores que implicam na qualidade do cuidado e na segurança do paciente. A enfermagem representa a maior força de trabalho, e é o conjunto de trabalhadores que mais sofre com a inadequada condição de trabalho causadas pelo absenteísmo.

Objetivo. Identificar os fatores relacionados às ausências não previstas pelos profissionais de enfermagem através de revisão integrativa de literatura.

Métodos. Estudo do tipo revisão integrativa da literatura. As bases de dados utilizadas foram Literatura Latino-Americana e do Caribe em Ciências da Saúde (Lilacs) e base de dados de enfermagem (Bdenf), utilizando os descritores absenteísmo e enfermagem. Resultados e discussão. Após leitura completa dos artigos, 6 (seis) responderam a questão norteadora, sendo escolhidos para compor este trabalho. Foi possível identificar que o sexo feminino é o mais predominante na equipe de enfermagem, apresentando assim, a maior taxa de abstinência. A categoria profissional que apresentou um maior número de faltas foi a de técnicos e auxiliares de enfermagem. As principais doenças citadas 
nos estudos foram doenças do sistema osteomuscular e do tecido conjuntivo, doenças do aparelho respiratório, doenças infecciosas e parasitárias e transtornos mentais e comportamentais.

Palavras-chave: absenteísmo. enfermagem, recursos humanos.

\begin{abstract}
Introduction. Absenteeism refers to the frequency or duration of lost work time when professionals do not attend work and correspond to absences when they were expected to be present. In health care, this issue has increasingly aroused the interest of hospital administrators, as it is one of the factors that imply quality of care and patient safety. Nursing represents the largest work force, and it is the set of workers that suffers the most from the inadequate working condition caused by absenteeism. Objective. To identify the profile of absences not predicted by nursing professionals through an integrative literature review. Methods. An integrative review of the literature. The databases used were Latin American and Caribbean Literature in Health Sciences (Lilacs) and Nursing Database (Bdenf), using the descriptors Absenteeism and Nursing. Results and discussion. After complete reading of the articles, 6 (six) answered the guiding question, being chosen to compose this work. It was possible to identify that the female sex is the most predominant in the nursing team, thus presenting the highest abstinence rate. The professional category that presented the greatest number of absences was that of technicians and nursing assistants. The main diseases cited in the studies were musculoskeletal and connective tissue diseases, respiratory diseases, infectious and parasitic diseases, and mental and behavioral disorders.
\end{abstract}

Keywords: absenteeism, nursing, human resources.

\title{
INTRODUÇÃO
}

O absenteísmo refere-se à frequência ou duração do tempo de trabalho perdido quando os profissionais não comparecem ao trabalho e corresponde às ausências quando se esperava que os mesmos estivessem presentes. Essas ausências não previstas se relacionam às faltas, às licenças (médicas, maternidade, nojo, gala, acompanhamento de familiar, qualificação profissional, etc.) e às suspensões de trabalho ${ }^{1}$.

As causas do absenteísmo podem ser diversas, tais como: fatores de trabalho, sociais, culturais, de personalidade, doenças, geográficos, organizacionais, físicos, psíquicos, ocupacionais, ambientais, características individuais e de personalidade. Além disso, as causas das ausências não previstas podem nem 
sempre estar ligadas ao profissional, mas sim à instituição, com processos de trabalhos deficientes, sobrecarga e repetitividade das ações, desmotivação, condições desfavoráveis e precárias, entre outros².

$\mathrm{Na}$ área da saúde, este assunto tem despertado cada vez mais o interesse dos administradores hospitalares, por ser um dos fatores que implicam na qualidade do cuidado e na segurança do paciente ${ }^{3}$. Na enfermagem 0 absentismo deve ser um ponto importante a ser considerado e analisado no gerenciamento de pessoal, em especial no serviço hospitalar, que funciona 24 horas $^{4}$. Neste ambiente, a enfermagem representa a maior força de trabalho, e é o conjunto de trabalhadores que mais sofre com a inadequada condição de trabalho causada pelo absenteísmo ${ }^{5}$.

A ausência não prevista dos profissionais traz muitos problemas, pois a ausência de um profissional na equipe sobrecarrega o trabalho dos demais, que têm que trabalhar em ritmo mais acelerado, responsabilizando-se por um maior volume de trabalho no processo de cuidar do paciente, $\mathrm{e}$ consequentemente, diminui a qualidade e a segurança do serviço prestado ao usuário de saúde ${ }^{5}$.

Nesse contexto, se faz necessário pensar no ausentismo não somente em seu quantitativo, mas também nos fatores desencadeadores dessas faltas. Para tanto, pretende-se responder com este estudo, a seguinte questão: quais são os fatores relacionados ao absenteísmo na equipe de enfermagem?

Nesse sentido, analisar os fatores relacionados ao absenteísmo, bem como sua ocorrência e prejuízos na enfermagem, pode facilitar a elaboração de um diagnóstico situacional pelos gestores, além de possibilitar estratégias para a diminuição do problema, melhoria da qualidade de vida e saúde dos profissionais da enfermagem, diminuição de sobrecarga de trabalho e assistência segura ao paciente.

\section{METODOLOGIA}

Estudo do tipo revisão integrativa da literatura. Esse tipo de estudo emerge como uma metodologia que proporciona a síntese do conhecimento e a incorporação da aplicabilidade de resultados de estudos significativos na prática ${ }^{6}$.

Para a elaboração desta revisão, serão seguidos os seguintes procedimentos metodológicos: formulação da questão e dos objetivos da revisão; estabelecimento de critérios para seleção dos artigos; categorização dos estudos; avaliação dos estudos incluídos na revisão integrativa; análise dos dados e apresentação dos resultados ${ }^{6}$.

As bases de dados utilizadas foram Literatura Latino-Americana e do Caribe em Ciências da Saúde (Lilacs) e Base de dados de Enfermagem (Bdenf). Os descritores selecionados foram, com base na terminologia em saúde 
consultada nos Descritores em Ciências da Saúde (DeCS-BIREME) e da Medical Subject Headings (MeSH): absenteísmo e enfermagem.

Os critérios de inclusão foram textos nacionais sobre o absenteísmo dos profissionais de enfermagem, publicados nos últimos 05 anos, e que respondam à questão norteadora deste estudo. Os critérios de exclusão foram textos que tratam de absenteísmo em outras áreas, que não seja da enfermagem e que sejam revisões integrativas.

Utilizando os descritores Absenteísmo e Enfermagem nas bases de dados escolhidas, respeitando os critérios de inclusão e exclusão, foram encontrados 39 artigos. Após a análise dos títulos e resumos dos trabalhos publicados, 11 foram selecionados para leitura do texto completo e análise. Após leitura completa dos artigos, 6 (seis) responderam à questão norteadora, sendo escolhidos para compor este trabalho.

\section{RESULTADOS E DISCUSSÃO}

Os artigos selecionados foram publicados entre os anos 2012 e 2015 nas seguintes revistas: Revista Brasileira de Enfermagem, Revista Mineira de Enfermagem, Acta Paulista de Enfermagem, Revista de Enfermagem UERJ e Revista Brasileira em Promoção da Saúde. Os objetivos, em geral, eram verificar e/ou analisar os índices de absenteísmo da equipe de enfermagem, bem como os fatores relacionados.

As metodologias aplicadas nos estudos respeitaram os critérios de exclusão, que não incluíram estudos de revisão. As abordagens foram todas quantitativas, e os estudos foram, em quase sua totalidade, retrospectivos e descritivos, com exceção de um estudo, que foi prospectivo. O Quadro 1 apresenta a síntese dos artigos selecionados.

Quadro 1. Síntese dos artigos selecionados, de acordo com título, ano, autor, revista, objetivos, metodologia, resultados e conclusão.

\begin{tabular}{|c|c|c|c|c|}
\hline Título/ano & Autor/revista & Objetivos & Metodologia & Resultados \\
\hline $\begin{array}{l}\text { O } \\
\text { absenteísmo } \\
\text { - doença da } \\
\text { equipe de } \\
\text { enfermagem } \\
\text { de um } \\
\text { hospital } \\
\text { universitário / } \\
2015^{7}\end{array}$ & $\begin{array}{l}\text { Divina de } \\
\text { Oliveira Marques, } \\
\text { Milca } \\
\text { Severino Pereira, } \\
\text { Adenícia Custódia } \\
\text { Silva e Souza, } \\
\text { Vanessa da Silva } \\
\text { Carvalho Vila, } \\
\text { Carlos Cristiano } \\
\text { Oliveira de } \\
\text { Faria Almeida, Enio } \\
\text { Chaves de Oliveira } \\
\text { / Revista Brasileira }\end{array}$ & $\begin{array}{l}\text { Analisar o } \\
\text { absenteísmo- } \\
\text { doença da } \\
\text { equipe de } \\
\text { enfermagem. }\end{array}$ & $\begin{array}{l}\text { Estudo } \\
\text { retrospectivo, } \\
\text { com abordagem } \\
\text { quantitativa, } \\
\text { realizado em um } \\
\text { hospital } \\
\text { universitário, } \\
\text { localizado no } \\
\text { município de } \\
\text { Goiânia, Goiás, } \\
\text { Brasil. Os dados } \\
\text { foram coletados } \\
\text { nos dossiês }\end{array}$ & $\begin{array}{l}\text { Dos } 602 \text { trabalhadores, } \\
435 \text { apresentaram } \\
1574 \text { atestados } \\
\text { médicos. As doenças } \\
\text { do sistema } \\
\text { osteomuscular e do } \\
\text { tecido conjuntivo, } \\
\text { seguidas dos } \\
\text { transtornos mentais e } \\
\text { comportamentais foram } \\
\text { as principais } \\
\text { causadoras de licenças } \\
\text { médicas. A categoria }\end{array}$ \\
\hline
\end{tabular}




\begin{tabular}{|c|c|c|c|c|}
\hline & de Enfermagem & & $\begin{array}{l}\text { funcionais dos } \\
\text { trabalhadores } \\
\text { referentes ao } \\
\text { período de } 2008 \\
\text { a } 2012 \text {. }\end{array}$ & $\begin{array}{l}\text { profissional que } \\
\text { apresentou maior } \\
\text { número de atestados } \\
\text { médicos foi a de } \\
\text { técnico em } \\
\text { enfermagem. } \\
\text { Predominou o sexo } \\
\text { feminino e a faixa } \\
\text { etária de } 41 \text { a } 50 \text { anos. } \\
\text { O ambulatório foi o } \\
\text { local com maior } \\
\text { frequência, seguido da } \\
\text { clínica médica e do } \\
\text { Pronto Socorro. }\end{array}$ \\
\hline $\begin{array}{l}\text { Absenteísmo } \\
\text { por } \\
\text { enfermidade } \\
\text { em } \\
\text { profissionais } \\
\text { de } \\
\text { enfermagem / } \\
2015^{8}\end{array}$ & $\begin{array}{l}\text { Vanessa Monteiro } \\
\text { Mantovani, } \\
\text { Joseane Kalata } \\
\text { Nazareth, Dirce } \\
\text { Nelci Port Maciel, } \\
\text { Cecília Biasibetti, } \\
\text { Amália de Fátima } \\
\text { Lucena, Isabel } \\
\text { Cristina Echer / } \\
\text { Revista Mineira de } \\
\text { Enfermagem }\end{array}$ & $\begin{array}{l}\text { Identificar a } \\
\text { prevalência do } \\
\text { absenteísmo, } \\
\text { bem como a } \\
\text { distribuição e os } \\
\text { motivos de } \\
\text { ausência entre } \\
\text { essa categoria } \\
\text { profissional. }\end{array}$ & $\begin{array}{l}\text { Estudo } \\
\text { transversal que } \\
\text { objetivou } \\
\text { caracterizar o } \\
\text { absenteísmo por } \\
\text { enfermidade em } \\
\text { profissionais de } \\
\text { enfermagem. A } \\
\text { amostra foi de } \\
299 \text { profissionais } \\
\text { de um hospital } \\
\text { universitário do } \\
\text { Sul do Brasil, } \\
\text { com coleta de } \\
\text { dados no } \\
\text { Sistema de } \\
\text { Informações } \\
\text { Gerenciais e em } \\
\text { arquivos do } \\
\text { serviço de } \\
\text { Medicina } \\
\text { ocupacional da } \\
\text { instituição, } \\
\text { referente ao ano } \\
\text { de 2012. A } \\
\text { análise dos } \\
\text { dados foi } \\
\text { estatística } \\
\text { descritiva. }\end{array}$ & $\begin{array}{l}\text { Foram } 220(73,57 \%) \\
\text { profissionais que se } \\
\text { afastaram por doença, } \\
\text { totalizando } 642 \\
\text { atestados e } 6.230 \text { dias } \\
\text { de afastamento. } \\
\text { Destes, } 50(22,7 \%) \\
\text { foram de enfermeiros, } \\
79(36 \%) \text { de técnicos } \\
\text { de enfermagem e } 91 \\
(41,3 \%) \text { de auxiliares } \\
\text { de enfermagem. As } \\
\text { enfermidades mais } \\
\text { prevalentes foram: } \\
\text { doenças respiratórias } \\
\text { nos enfermeiros e } \\
\text { doenças do sistema } \\
\text { osteomuscular e tecido } \\
\text { conjuntivo nos técnicos } \\
\text { e auxiliares de } \\
\text { enfermagem. }\end{array}$ \\
\hline $\begin{array}{l}\text { Fatores } \\
\text { relacionados } \\
\text { ao } \\
\text { absenteísmo } \\
\text { por doença } \\
\text { entre } \\
\text { trabalhadores } \\
\text { de } \\
\text { Enfermagem / }\end{array}$ & $\begin{array}{l}\text { Eliete } \\
\text { Boaventura Bargas } \\
\text {, Maria } \\
\text { Inês Monteiro / } \\
\text { Acta Paulista de } \\
\text { Enfermagem }\end{array}$ & $\begin{array}{l}\text { Avaliar a } \\
\text { associação do } \\
\text { absenteísmo por } \\
\text { doença com o } \\
\text { perfil } \\
\text { sociodemográfic } \\
\text { o e relacioná-lo } \\
\text { ao trabalho dos } \\
\text { profissionais de }\end{array}$ & $\begin{array}{l}\text { Estudo descritivo } \\
\text { exploratório, que } \\
\text { analisou } \\
\text { atestados } \\
\text { médicos de até } \\
15 \text { dias de } \\
\text { afastamento do } \\
\text { trabalho } \\
\text { apresentados por } \\
994 \text { profissionais }\end{array}$ & $\begin{array}{l}\text { A maioria dos } \\
\text { trabalhadores era do } \\
\text { sexo feminino, casada } \\
\text { e técnica de } \\
\text { Enfermagem. A idade } \\
\text { média foi de } 41,9 \text { anos } \\
\text { e um terço atuava no } \\
\text { serviço de internação } \\
\text { de adultos. Dos } 994 \\
\text { profissionais, } 645\end{array}$ \\
\hline
\end{tabular}




\begin{tabular}{|c|c|c|c|c|}
\hline $2014^{9}$ & & Enfermagem. & $\begin{array}{l}\text { de enfermagem } \\
\text { de um hospital } \\
\text { universitário. A } \\
\text { fonte de dados } \\
\text { foi o sistema de } \\
\text { frequência da } \\
\text { instituição. }\end{array}$ & $\begin{array}{l}\text { apresentaram pelo } \\
\text { menos um dia de } \\
\text { atestado médico. }\end{array}$ \\
\hline $\begin{array}{l}\text { Absenteísmo } \\
\text { por doença } \\
\text { na equipe de } \\
\text { enfermagem } \\
\text { de uma } \\
\text { operadora de } \\
\text { plano de } \\
\text { saúde / } \\
2014^{10}\end{array}$ & $\begin{array}{l}\text { Alessandro } \\
\text { Formentoni, Vivian } \\
\text { Aline Mininel, Ana } \\
\text { Maria Laus / } \\
\text { Revista de } \\
\text { Enfermagem UERJ }\end{array}$ & $\begin{array}{l}\text { Analisar o } \\
\text { absenteísmo- } \\
\text { doença na } \\
\text { equipe de } \\
\text { enfermagem de } \\
\text { uma operadora } \\
\text { de planos de } \\
\text { saúde do interior } \\
\text { de São Paulo, } \\
\text { que integra a } \\
\text { rede de } \\
\text { atendimento do } \\
\text { setor } \\
\text { suplementar de } \\
\text { saúde nesta } \\
\text { região. }\end{array}$ & $\begin{array}{l}\text { Estudo de } \\
\text { natureza } \\
\text { quantitativa, } \\
\text { descritivo, } \\
\text { retrospectivo, } \\
\text { que analisou o } \\
\text { absenteísmo- } \\
\text { doença na } \\
\text { equipe de } \\
\text { enfermagem de } \\
\text { uma operadora } \\
\text { de planos de } \\
\text { saúde do interior } \\
\text { de São Paulo. Os } \\
\text { dados } \\
\text { secundários } \\
\text { coletados dos } \\
\text { atestados } \\
\text { médicos, } \\
\text { referentes ao ano } \\
\text { de } 2007 \text {. }\end{array}$ & $\begin{array}{l}\text { A maioria dos } 98 \\
\text { profissionais afastados } \\
\text { era do sexo feminino, } \\
\text { pertencente à unidade } \\
\text { hospitalar e geraram } \\
172 \text { afastamentos, com } \\
\text { uma média de } 1,76 \text { por } \\
\text { profissional, } \\
\text { decorrentes de } \\
\text { doenças do aparelho } \\
\text { respiratório. A média } \\
\text { de dias perdidos de } \\
\text { trabalho foi } 5,39, \text { sendo } \\
\text { maior entre técnicos de } \\
\text { enfermagem da } \\
\text { unidade de pronto } \\
\text { atendimento. }\end{array}$ \\
\hline $\begin{array}{l}\text { Afastamento } \\
\text { do trabalho } \\
\text { em } \\
\text { profissionais } \\
\text { de } \\
\text { enfermagem } \\
\text { por etiologias } \\
\text { psicológicas / } \\
2013^{11}\end{array}$ & $\begin{array}{l}\text { Robson Douglas de } \\
\text { Oliveira, Eduardo } \\
\text { Borba Neves, } \\
\text { Cleverson Higa } \\
\text { Kaio, Leandra } \\
\text { Ulbrich / Revista } \\
\text { Brasileira em } \\
\text { Promoção da } \\
\text { Saúde }\end{array}$ & $\begin{array}{l}\text { Analisar a } \\
\text { incidência e o } \\
\text { tempo dos } \\
\text { afastamentos } \\
\text { ligados } \\
\text { especificamente } \\
\text { às causas } \\
\text { psicológicas } \\
\text { entre } \\
\text { profissionais de } \\
\text { enfermagem. } \\
\text { Além disso, } \\
\text { procurou } \\
\text { identificar fatores } \\
\text { de risco para os } \\
\text { afastamentos e } \\
\text { sugerir ações } \\
\text { que possam } \\
\text { mitigar os } \\
\text { problemas } \\
\text { encontrados. }\end{array}$ & $\begin{array}{l}\text { Foi feito um } \\
\text { estudo ecológico, } \\
\text { retrospectivo, no } \\
\text { maior hospital } \\
\text { público de } \\
\text { Curitiba- PR, } \\
\text { com dados de } \\
3.692 \\
\text { profissionais de } \\
\text { enfermagem } \\
\text { (2.294 auxiliares } \\
\text { de enfermagem, } \\
590 \text { técnicos de } \\
\text { enfermagem e } \\
808 \text { enfermeiros), } \\
\text { de janeiro de } \\
2007 \text { a setembro } \\
\text { de } 2010 \text {. }\end{array}$ & $\begin{array}{l}\text { Verificou-se que a } \\
\text { principal causa de } \\
\text { afastamentos foram os } \\
\text { episódios depressivos } \\
\text { (F32), com } 784 \\
\text { afastamentos. Quanto } \\
\text { ao tempo de } \\
\text { afastamento, a causa } \\
\text { que por mais tempo } \\
\text { afastou os enfermeiros } \\
\text { (média de } 40,62 \text { dias) } \\
\text { foi o transtorno afetivo } \\
\text { bipolar (F31). Os } \\
\text { auxiliares e os técnicos } \\
\text { em enfermagem se } \\
\text { afastaram devido ao } \\
\text { transtorno depressivo } \\
\text { recorrente (F33), em } \\
\text { média, por 40,47 e } \\
54,33 \text { dias, } \\
\text { respectivamente. }\end{array}$ \\
\hline $\begin{array}{l}\text { Ausências } \\
\text { dos } \\
\text { colaboradore }\end{array}$ & $\begin{array}{l}\text { Flávio Trevisani } \\
\text { Fakih, Luiza Hiromi } \\
\text { Tanaka, Maria }\end{array}$ & $\begin{array}{l}\text { Verificar e } \\
\text { analisar as } \\
\text { ausências dos }\end{array}$ & $\begin{array}{l}\text { Estudo de } \\
\text { abordagem } \\
\text { quantitativa, }\end{array}$ & $\begin{array}{l}\text { O PSA teve, em média, } \\
96,8 \text { colaboradores por } \\
\text { mês. As ausências }\end{array}$ \\
\hline
\end{tabular}




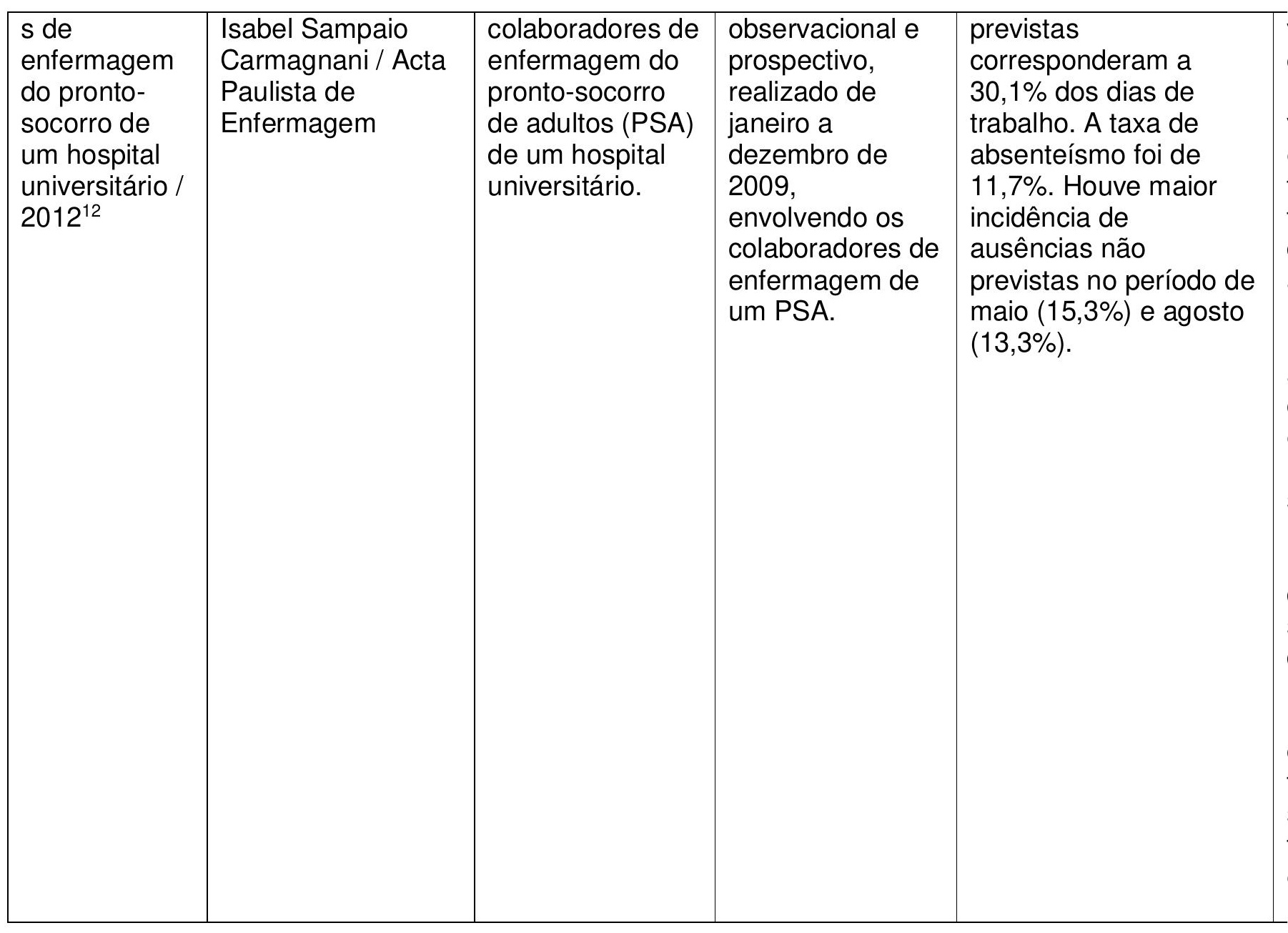

No contexto hospitalar, os profissionais de enfermagem merecem destaque, pois constituem o maior contingente de trabalhadores da área da saúde. A enfermagem é considerada uma profissão fatigante e tensa, em decorrência do contato com o sofrimento e com a morte, das jornadas de plantão, da aceleração dos ritmos de trabalho, da polivalência do profissional e do esforço musculoesquelético para a realização do cuidado, entre outros ${ }^{13}$. Devido a estes fatores, conhecer os fatores relacionados ao absenteísmo faz-se necessário para que se proponham mudanças efetivas na política de gestão de pessoal e nos processos de trabalho, bem como na promoção da saúde e segurança dos colaboradores, aumentando sua satisfação no trabalho e seu compromisso com a instituição.

Estudos $^{7-9}$ apontam que a equipe de enfermagem é formada, em sua maioria, por mulheres. Marques et $a{ }^{7}$ descreve uma forte predominância do sexo feminino nos índices de absenteísmo (92,9\%). Os estudos de Montovani et aß e Bargas e Monteiro ${ }^{9}$ corroboram com esta informação acrescentando que esse alto índice se justificam pela presença importante do sexo feminino na formação da equipe de enfermagem, bem como salientam que a maioria das mulheres inseridas no mercado de trabalho agrega diferentes papéis sociais e geralmente necessita conciliar atividades domésticas e cuidados com filhos e familiares, fato que pode provocar seu adoecimento, acarretando maior índice de ausências no trabalho. 
Os dados do estudo de Marques et al demonstram que, independente do sexo, a maior frequência de afastamentos foi registrada na faixa etária de 41 a 50 anos (35,9\%), seguida de 31 a 40 anos (30,3\%). Constatou-se que 59,5\% dos trabalhadores que apresentaram atestados tinham acima de 40 anos de idade. Em outro estudo ${ }^{8}$ a média de idade foi 43 anos. Investigação realizada no Canadá identificou que trabalhadores do sexo feminino com faixa etária mais elevada eram mais propensos a apresentar absenteísmo por doença ${ }^{15}$.

A categoria de profissionais com maior índice de absenteísmo foi a de técnicos e auxiliares de enfermagem. Marques et al aponta que os técnicos e auxiliares de enfermagem foram os profissionais que mais apresentaram atestados médicos, $81 \%$ do total de trabalhadores da equipe de enfermagem. Este dado é preocupante, pois esses profissionais representam o maior contingente da força de trabalho da equipe de enfermagem. A maior ocorrência de absenteísmo entre técnicos e auxiliares de enfermagem pode estar relacionada à menor remuneração, menor exigência de instrução técnico-científica e à maior necessidade de esforço físico na execução do cuidado ao paciente. Suas ausências comprometem a assistência prestada e, consequentemente, desestruturam a equipe por gerar sobrecarga de atividades aos demais trabalhadores. Outros estudos ${ }^{8-11}$ corroboram com estes resultados, justificando que os grupos mais qualificados, com formação superior, estão menos expostos às más condições de trabalho, ficando menos doentes e, assim, ausentando-se menos. Dado similar é relatado em estudo realizado no Estado do Rio de Janeiro, no qual os autores relataram que os enfermeiros tendiam a assumir papel de liderança na equipe, que exige maior assiduidade; apresentavam menor risco de contaminação e de doenças; e, também, assumiam tarefas administrativas ${ }^{12}$.

As principais doenças citadas nos estudos foram doenças do sistema osteomuscular e do tecido conjuntivo, doenças do aparelho respiratório, doenças infecciosas e parasitárias e transtornos mentais e comportamentais.

Estudo $^{12}$ realizado no pronto socorro de um hospital universitário apontou que os problemas relacionados aos sistemas respiratório e osteomuscular figuram entre as principais causas de afastamento. Em grande parte das situações de urgência e emergência, os profissionais realizam técnicas de mobilização de pacientes dependentes, além de atuarem em número insuficiente e em área física exígua. As posturas corporais incorretas, o excesso de atividades, a longa permanência em pé e a inadequação do mobiliário são apontados como fatores de risco ergonômico, fadiga e danos à saúde.

Encontrou-se predomínio de doenças do sistema osteomuscular e tecido conjuntivo entre os técnicos e auxiliares de enfermagem. Esse tipo de doença é frequente no cotidiano dos profissionais de enfermagem, devido ao risco ergonômico a que os mesmos estão expostos no trabalho. Ao encontro disto, o decênio entre 2000 e 2010 foi designado como a década do osso e da articulação, visto que as doenças e lesões osteoarticulares incidem na população e se constituem em uma das causas mais frequentes de absenteísmo laboral e invalidez permanente ${ }^{15}$. Complementando esses achados, em um estudo grego realizado com 350 profissionais de enfermagem, 
$51 \%$ referiram dor na coluna lombar e $23 \%$ queixaram-se de dores nos joelhos, ambas atribuídas ao esforço físico na realização do trabalho ${ }^{16}$.

Outro estudo ${ }^{10}$ também aponta as doenças citadas anteriormente como as principais causas de atestado, acrescentando outras patologias: 13,4\% decorrentes de doenças do aparelho respiratório; $12,2 \%$ de doenças do sistema osteomuscular e tecido conjuntivo; $11 \%$ de doenças infecciosas e parasitárias; $11 \%$ de sinais, sintomas e achados anormais não classificados; 9.3\% de doenças do aparelho geniturinário; $8,1 \%$ decorrentes de gravidez, parto e puerpério; $5,8 \%$ de doenças olhos e anexos; e 5,2\% de causas externas.

No estudo de Marques et al , a segunda doença apresentada como responsável pelo afastamento dos trabalhadores foram os transtornos mentais e comportamentais (TMC) com 284 (18,04\%) dos casos. Destacaram-se os episódios depressivos, transtornos bipolares e estresse.

Estudo ${ }^{11}$ realizado para se identificar as causas do afastamento por transtorno mental identificou que as três principais causas foram devido aos episódios depressivos com 784 afastamentos; ao transtorno afetivo bipolar com 331 profissionais afastados; e ao transtorno depressivo recorrente, responsável por 175 afastamentos. Entretanto não existem diferenças estatísticas entre as principais causas desses afastamentos quando se compara aos diferentes profissionais de enfermagem. $O$ transtorno afetivo bipolar foi a etiologia que por mais tempo afastou os enfermeiros das suas funções (40,62 dias), enquanto o transtorno depressivo recorrente foi a condição que por mais tempo afastou os auxiliares e técnicos em enfermagem (40,47 dias e 54,33 dias, respectivamente). Quanto à gravidade dos afastamentos, o transtorno afetivo bipolar teve o máximo de 365 dias de afastamento; nos episódios depressivos, os afastamentos duraram até 244 dias; o transtorno depressivo recorrente, 208 dias; e as reações ao stress grave e transtornos de adaptação representaram afastamentos de até 100 dias.

Quanto ao tempo de afastamento, Montovani et a $\beta$ em sua pesquisa aponta que houve predomínio de atestados de curta duração, inferior ou igual a 15 dias de afastamento, nas três categorias profissionais, o que dificulta o processo de trabalho da equipe de enfermagem, visto que nessas situações não ocorre contratação de profissional, sobrecarregando a equipe com maior demanda de trabalho. Nos atestados de longa duração, superior a 15 dias de afastamento, o profissional é remunerado pelo Instituto Nacional de Seguridade Social (INSS) e a unidade recebe um funcionário contratado para cobertura da licença. Esse resultado também é encontrado no estudo de Formenton, Mininel e Laus ${ }^{10}$ e Fakih, Tanaka, Carmagnani ${ }^{12}$.

\section{CONCLUSÃO}

Os achados neste estudo fundamentam a perspectiva do absenteísmo com determinantes multifatoriais e complexos, que precisam ser analisados para 
que seja possível construir um ambiente de trabalho de saúde e bem-estar dos trabalhadores de enfermagem.

Dentre os achados, foi possível identificar que o sexo feminino é o mais predominante na equipe de enfermagem, apresentando assim, a maior taxa de abstinência. A categoria profissional que apresentou um maior número de faltas foi a de técnicos e auxiliares de enfermagem. As principais doenças citadas nos estudos foram doenças do sistema osteomuscular e do tecido conjuntivo, doenças do aparelho respiratório, doenças infecciosas e parasitárias e transtornos mentais e comportamentais.

Essas informações possibilitam um maior conhecimento para melhorar a organização hospitalar, inclusive para o dimensionamento do pessoal de enfermagem, de modo a reduzir ao máximo os efeitos negativos das ausências sobre os trabalhadores.

\section{REFERÊNCIAS}

1- Gaidzinskl RR, Lima AFC, Soares AVN, Fugulin FMT, Sancinetti TR, Castilho V. Gestão de pessoal de enfermagem e o sistema de assistência de enfermagem. In: Gaidzinski RR, Soares AVN, Lima AFC, editors. Diagnóstico de enfermagem na prática clínica. São Paulo: Artmed; 2008. p. 47-61.

2- Sancinetti TR et al. Taxa de absenteísmo da equipe de enfermagem como indicador de gestão de pessoas. Rev. Esc. Enferm. USP. 2011 ago; 45(4): 1007-1012. Disponível em: < http://www.scielo.br/scielo.php?pid=S008062342011000400031\&script=sci_abstract\&tlng=pt>. Acesso em 20/11/2017.

3- Laus AM; Anselmi ML. Ausência dos trabalhadores de enfermagem em um hospital escola. Rev. Esc. Enferm. USP. 2008 dez; 42(4): 681-689. Disponível em: < http://www.scielo.br/scielo.php?pid=S0080-

62342008000400010\&script=sci_abstract\&tlng=pt>. Acesso em 20/11/2017.

4- Campos EC, Juliani CMCM, Palhares VC. O absenteísmo da equipe de enfermagem em unidade de pronto socorro de um hospital universitário. Rev. Eletr. Enf. 2009; 11(2): 295-302. Disponível em: < https://www.fen.ufg.br/fen_revista/v11/n2/pdf/v11n2a09.pdf>. Acesso em: 20/11/2017.

5- Martinato MCNB et al. Absenteísmo na enfermagem: uma revisão integrativa. Rev. Gaúcha Enferm. 2010 mar; 31(1): 160-166. Disponível em: < http://www.scielo.br/scielo.php?script=sci_arttext\&pid=S1983$14472010000100022>$. Acesso em: 20/11/2017.

6- Souza MT, Silva MD, Carvalho R. Revisão integrativa: o que é e como fazer. Einstein. 2010 jan/mar; 8(1): 102-6. Disponível em: http://www.scielo.br/scielo.php?pid=S167945082010000100102\&script=sci_arttext\&tlng=pt. Acesso em: 20/11/2017. 
7- Marques DO et al. O absenteísmo - doença da equipe de enfermagem de um hospital universitário. Rev. Bras. Enferm. 2015 out; 68(5): 876-

882. Disponível em < http://www.scielo.br/scielo.php?pid=S0034-

71672015000500876\&script=sci_abstract $>$. Acesso em 20/11/2017.

8- Mantovani VM et al. Absenteísmo por enfermidade em profissionais de enfermagem. Reme: Rev. Min. Enferm. 2015 jul/set; 19(3): 641-652.

9- Bargas EB, Monteiro MI. Fatores relacionados ao absenteísmo por doença entre trabalhadores de Enfermagem. Acta paul. enferm. 2014 dez; 27(6): 533538. Disponível em: < http://www.scielo.br/scielo.php?script=sci_arttext\&pid=S010321002014000600533 . Acesso em 20/11/2017.

10- Formentoni A, Minine VA, Laus AM. Absenteísmo por doença na equipe de enfermagem de uma operadora de plano de saúde. Rev enferm UERJ. 2014 jan/fev; 22(1): 42-9. Disponível em: <http://www.facenf.uerj.br/v22n1/v22n1a07.pdf>. Acesso em: 20/11/2017.

11- Oliveira RD et al. Afastamento do trabalho em profissionais de enfermagem por etiologias psicológicas. Rev Bras Promoc Saude. 2013 out/dez; 26(4): 554562. Disponível em < http://periodicos.unifor.br/RBPS/article/view/2337/pdf>. Acesso em: 20/11/2017.

12- Fakih F, Tanaka LH, Carmagnani MIS. Ausências dos colaboradores de enfermagem do pronto-socorro de um hospital universitário. Acta paul. enferm. 2012; 25(3): 378-385. Disponível em: <

http://www.scielo.br/scielo.php?script=sci_arttext\&pid=S0103-

21002012000300010 >. Acesso em: 20/11/2017.

13- Magnago TSBS et al . Aspectos psicossociais do trabalho e distúrbio musculoesquelético em trabalhadores de enfermagem. Rev. Latino-Am. Enfermagem. 2010 mai/jun; 18(3): 429-435. Disponível em: < https://www.revistas.usp.br/rlae/article/view/4172>. Acesso em: 20/11/2017.

14- Sancinetti TR et al. Absenteísmo - doença na equipe de enfermagem: relação com a taxa de ocupação. Rev. esc. enferm. USP. 2009 dez; 43(2): 1277-1283. Disponível em: < http://www.scielo.br/scielo.php?pid=S008062342009000600023\&script=sci_abstract\&tlng=pt>. Acesso em 20/11/2017.

15- Gorman E, Yu S, Alamgir H. When healthcare workers get sick: exploring sickness absenteeism in British Columbia, Canada. Work. 2010; 35(2): 117123. Disponível em: < https://www.ncbi.nlm.nih.gov/pubmed/20164606>. Acesso em 20/11/2017.

16- Alexopoulos EC et al. Knee and low back complaints in professional hospital nurses: occurrence, chronicity, care seeking and absenteeism. Work. 2011; 38(4): 329-335. Disponível em: https://www.ncbi.nlm.nih.gov/pubmed/21508522. Acesso em 20/11/2017. 
Recebido: 20 novembro 2017. Publicado: 04 dezembro 2017

Correspondência: Viviane Santos Mendes Carneiro. E-mail: vsm.mendes@gmail.com

Conflito de Interesses: os autores declararam não haver conflito de interesses.

(C) This is an Open Access article distributed under the terms of the Creative Commons Attribution License, which permits unrestricted use, distribution, and reproduction in any medium, provided the original work is properly cited 